\title{
Analysis of Handoff Call Rate in Microcell of GSM Networks by Steele and Nofal Traffic Model
}

\author{
Elsanosy M. Elamin ${ }^{*}$, Basil B. Ahmed ${ }^{2}$. AbdelRahman Y. Adam ${ }^{3}$, Mohamed H. Mohamed ${ }^{4}$ \\ ${ }^{1,2,3,4}$ Dept. of Electrical Engineering, Faculty of Engineering, University of Kordofan, Sudan.
}

*Corresponding Author: Elsanosy M. Elamin, Dept. of Electrical Engineering, Faculty of Engineering, University of Kordofan, Sudan.

\begin{abstract}
This paper aims to perform an in depth analysis of handoff calls arrival rate in microcell of GSM networks in order to evaluate the wireless network performance and, in turn, to assist in reducing both of call dropping probability and call blocking probability. The main tool that used in this work to analyze the system is the mathematical Steele and Nofal traffic model. In this model, there are seven various parameters; the arrival rate of originating calls in a cell, the blocking probability of originating calls, the fraction of handoff calls to the current cell from the adjacent cells, the probability of handoff failure, the probability that a new call that is not blocked would require at least one handoff, the probability that a call that has already been handed off successfully would require another handoff, the probability that a new call that is not blocked will require at least one handoff. These parameters are investigated and considered in wide values ranges in order to evaluate their effect on the overall handoff arrival call rate. Through the analytical phases, the seven different parameters show dissimilar degrees of impact on the handoff arrival call rate. Accordingly, it is found that the probability that a new call that is not blocked will require at least one handoff is the most effective factor and then the probability of handoff failure.
\end{abstract}

Keywords: Wireless networks, handoff call rate, call drop, call block, traffic model.

\section{INTRODUCTION}

The system performance analysis in the wireless networks nowadays is becoming a crucial factor that assists in depth evaluation of the system and help in developing the system performance. In the wireless communication systems, the handoff process is still remaining the dominant parameter in the performance analysis and is greatly related to both holding time and cell residence time [1]. Handoff process is significantly starting to affect system performance since the second generation due to the growing of the low data rates specifically the SMS [3]. As the wireless networks rapidly deploying because of the reassigned data bandwidth, the users are dramatically growing and the network had to provide continuous services to the users to ensure the QoS and technically increase the trustness between the service provider and the users [4]. The handoff process is also analyzed by using multidifferent mathematical and/or simulation models to improve the wireless communication systems. The other disadvantages aspects of the handoff process are the handoff failure that related to both call dropping probability and call block probability $[2,6]$. The call dropping probability is defined as probability that a call will either termination or blocking. The call dropping probability in conversational land-line networks extremely very low and is significantly less than 0.0 , but in mobile communication networks using radio channel is higher and is about 0.1 to 0.5 due to: lack of radio coverage either in downtown link or up link and imperfection in function of the network as handoff failure [8]. Whereas the call blocking probability is defined as probability that a new call request be denied because of resources lacking. Both of call dropping probability and call blocking probability are contributed to the performance degradation and deterioration. Accordingly, there are different models used in analysis and improving the system performance. So, there are some of them such as [5]:

1. Hong and Rapp port mathematical traffic model.

2. Steele and Nofal traffic model.

3. Eldolil traffic model.

4. Xie and kuek's traffic model.

International Journal of Research Studies in Electrical and Electronics Engineering (IJRSEEE) Page | 35 


\section{Zeng et al.'s Approximated Traffic Model.}

The fundamental issue that this paper is addressed is the handoff arrival call rate $\lambda_{H}$ which can be expressed as [2]:

$\lambda_{H}=\frac{\text { Number of successful handoff calls }}{\text { Number of total handoff call requests }}$

So the other system parameters are all together must assist in dramatically increasing this ratio in order to improve the system performance. Refer to the previous studies, it is found that the call termination probability is lower than 0.05 and the handoff failure probability is also lower than 0.02 . For better performance improvement, the handoff process can be analyzed by different models so as to strongly develop the system to comply with the continuous dynamic requirements to keep the QoS as good as possible [7].

\section{Steele And Nofal Traffic Model}

Since the wireless communication networks are becoming more popular in public life, there is rapidly dynamic continuous increasing in both data and voice traffic. So, the mathematical and/or simulation traffic modeld are required to help understanding system changed performance. Steele and Nofal mathematical traffic model is used to evaluate the handoff arrival call rate to continually assist in reducing the call dropping probability and call blocking probability. This model is depending on different parameters that are all compose the entire nation about the key parameters with very high important positive effect on the overall performance. The mode is clearly shown below in equation as:

$\lambda_{H}=\sum_{m=1}^{n} \lambda o(1-B o)\left[P h \beta+3 P 1 \beta\left(1-P^{\prime} f\right) P h h \beta\right]$

Where: $\lambda_{o}$ : the arrival rate of originating calls in a cell, $B_{O}$ : the blocking probability of originating calls, $\beta$ : the fraction of handoff calls to the current cell from the adjacent cells, $P_{f}$ : the probability of handoff failure, $P_{h}$ : the probability that a new call that is not blocked would require at least one handoff, $P_{h h}$ : the probability that a call that has already been handed off successfully would require another handoff, $P_{l}$ : the probability that a new call that is not blocked will require at least one handoff. In the mathematical traffic model, the evaluated handoff arrival call rate is directly depending on the wide range of it is parameters. The seven various parameters of the system are classified into two principal groups; group one and group two as listed in table1. Group one represents the calculated values that are used as constant parameters in the model. Whereas, group two which is represents the inconstant values that varied in wide different ranges.

Table1. The group's parameters and cases values

\begin{tabular}{|c|c|c|c|c|c|c|c|c|c|}
\hline \multicolumn{2}{|c|}{ Group Two (Inconstant) } & \multicolumn{2}{|c|}{ Group One (Constant) } & Case1 & Case2 & Case3 & $\begin{array}{c}\text { Cas } \\
\text { e4 }\end{array}$ \\
\hline Parameter & Min & Max & Parameter & Min & Max & & & & \\
\hline$B_{O}$ & 0.01 & 0.04 & $\lambda_{\boldsymbol{O}}$ & 0.1 & 0.3 & $\mathbf{0 . 3}$ & $\mathbf{0 . 1}$ & 0.1 & 0.1 \\
\hline$P_{l}$ & 0.01 & 0.15 & $\beta$ & 0.8 & 0.98 & 0.8 & $\mathbf{0 . 9 8}$ & 0.8 & 0.8 \\
\hline$P_{f}$ & 0.01 & 0.2 & $P_{h}$ & 0.9 & 0.98 & 0.9 & 0.9 & $\mathbf{0 . 9 8}$ & 0.9 \\
\hline- & - & - & $P_{h h}$ & 0.01 & 0.98 & 0.01 & 0.01 & 0.01 & $\mathbf{0 . 9 8}$ \\
\hline
\end{tabular}

Through the normal performance of the system up to the critical one, the model explains the multidifferent performance conditions and capable to express them by the wide value ranges of parameters. In normal performance the system is capable to carry out all the handoff process with no call dropping and blocking probabilities. Whereas, the critical system performance is that any additional only one handoff call request made the system not only capable to carry out the handoff process but also drop the call in progress and block any initiating call in the same microcell in the system. These conditions are categorized into multi-different cases depending on each parameter range as shown in table2.

\section{RESUlts AND Discussion}

Steele and Nofal traffic model is used as mathematical tool to assist in analyzing the system performance under various conditions and later to contribute in forming the conceptual frame to control the both the call dropping and call blocking probabilities. Tables 2, 3, and 4 shows the mathematical results that are carried out and obtained for the cases 1,2, 3, and 4. In case1, all group one parameters are in its minimum values except the arrival rate of originating calls, $\left(\lambda_{o}=0.3\right)$ in its maximum value. Case 2 is dealt as; all the parameters $\lambda_{o}, P h, P h h$, are in their minimum values except 
the fraction of handoff calls to the current cell from the adjacent cells $(\beta=0.98)$ in its maximum. Case 3 also highlighted only the probability of unblocked new call $\left(P_{h}=0.98\right)$ in its maximum value and the other constant parameters are in its minimum values. In case 4 , the only probability that a call that has already been handed off successfully is in its maximum value $\left(P_{h h}=0.98\right)$.

Table2. Handoff call rate $\lambda_{H}$ versus $P 1$

\begin{tabular}{|c|c|c|c|c|}
\hline $\mathrm{P}_{1}$ & $\lambda_{\mathrm{H}}$ (case1) & $\lambda_{\mathrm{H}}$ (case2) & $\lambda_{\mathrm{H}}$ (case3) & $\lambda_{\mathrm{H}}$ (case4) \\
\hline 0.0100 & 0.2139 & 0.0891 & 0.0792 & 0.0715 \\
\hline 0.0193 & 0.2139 & 0.0892 & 0.0792 & 0.0716 \\
\hline 0.0287 & 0.2140 & 0.0892 & 0.0793 & 0.0718 \\
\hline 0.0380 & 0.2141 & 0.0892 & 0.0793 & 0.0720 \\
\hline 0.0473 & 0.2141 & 0.0892 & 0.0793 & 0.0722 \\
\hline 0.0567 & 0.2142 & 0.0893 & 0.0793 & 0.0723 \\
\hline 0.0660 & 0.2142 & 0.0893 & 0.0793 & 0.0725 \\
\hline 0.0753 & 0.2143 & 0.0893 & 0.0793 & 0.0727 \\
\hline 0.0847 & 0.2143 & 0.0893 & 0.0794 & 0.0729 \\
\hline 0.0940 & 0.2144 & 0.0894 & 0.0794 & 0.0730 \\
\hline 0.1033 & 0.2144 & 0.0894 & 0.0794 & 0.0732 \\
\hline 0.1127 & 0.2145 & 0.0894 & 0.0794 & 0.0734 \\
\hline 0.1220 & 0.2145 & 0.0895 & 0.0794 & 0.0736 \\
\hline 0.1313 & 0.2146 & 0.0895 & 0.0794 & 0.0738 \\
\hline 0.1407 & 0.2146 & 0.0895 & 0.0795 & 0.0739 \\
\hline 0.1500 & 0.2147 & 0.0895 & 0.0795 & 0.0741 \\
\hline
\end{tabular}

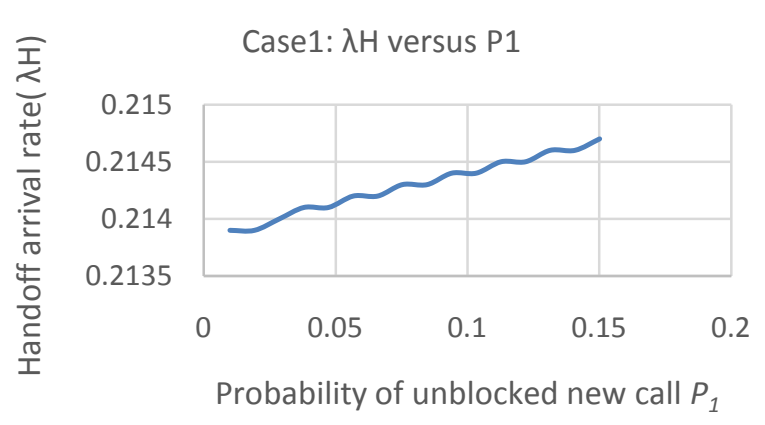

Figure1. Handoffs call arrival rate $\lambda_{H}$ versus $P 1$, case 1

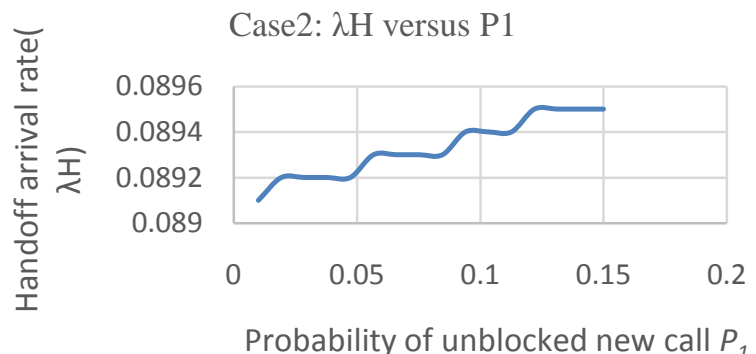

Figure2. Handoff call arrival rate $\lambda_{H}$ versus $P 1$, case 2

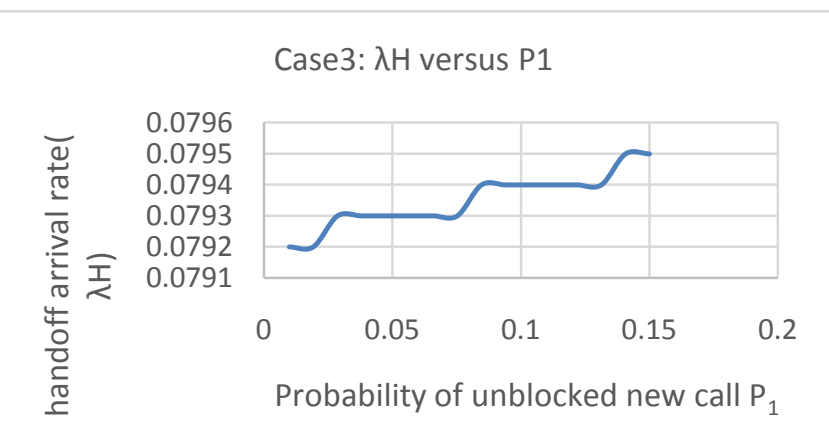

Figure3. Handoff calls arrival rate $\lambda_{H}$ versus $P 1$, case 3 


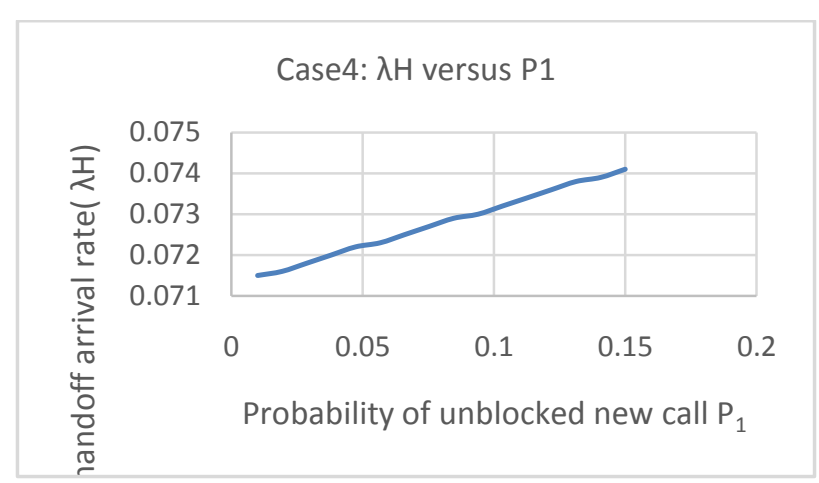

Figure4. Handoff call arrival rate $\lambda_{H}$ versus $P 1$, case 4

Table3. Handoff call rate $\lambda_{H}$ versus $P^{\prime} f$

\begin{tabular}{|c|c|c|c|c|}
\hline $\mathrm{P}_{\mathrm{f}}$ & $\lambda_{\mathrm{H}}(\mathrm{case} 1)$ & $\lambda_{\mathrm{H}}(\mathrm{case})$ & $\lambda_{\mathrm{H}}$ (case3) & $\lambda_{\mathrm{H}}$ (case4) \\
\hline 0.0100 & 0.2139 & 0.0891 & 0.0792 & 0.0715 \\
\hline 0.0227 & 0.2112 & 0.0891 & 0.0791 & 0.0715 \\
\hline 0.0353 & 0.2084 & 0.0891 & 0.0789 & 0.0715 \\
\hline 0.0480 & 0.2057 & 0.0891 & 0.0787 & 0.0715 \\
\hline 0.0607 & 0.2029 & 0.0891 & 0.0786 & 0.0715 \\
\hline 0.0733 & 0.2002 & 0.0891 & 0.0784 & 0.0715 \\
\hline 0.0860 & 0.1975 & 0.0891 & 0.0783 & 0.0715 \\
\hline 0.0987 & 0.1947 & 0.0891 & 0.0781 & 0.0715 \\
\hline 0.1113 & 0.1920 & 0.0891 & 0.0779 & 0.0714 \\
\hline 0.1240 & 0.1893 & 0.0891 & 0.0778 & 0.0714 \\
\hline 0.1367 & 0.1865 & 0.0891 & 0.0776 & 0.0714 \\
\hline 0.1493 & 0.1838 & 0.0891 & 0.0775 & 0.0714 \\
\hline 0.1620 & 0.1811 & 0.0891 & 0.0773 & 0.0714 \\
\hline 0.1747 & 0.1783 & 0.0891 & 0.0771 & 0.0714 \\
\hline 0.1873 & 0.1756 & 0.0891 & 0.0768 & 0.0714 \\
\hline 0.2000 & 0.1728 & 0.0891 & & 0.0714 \\
\hline
\end{tabular}

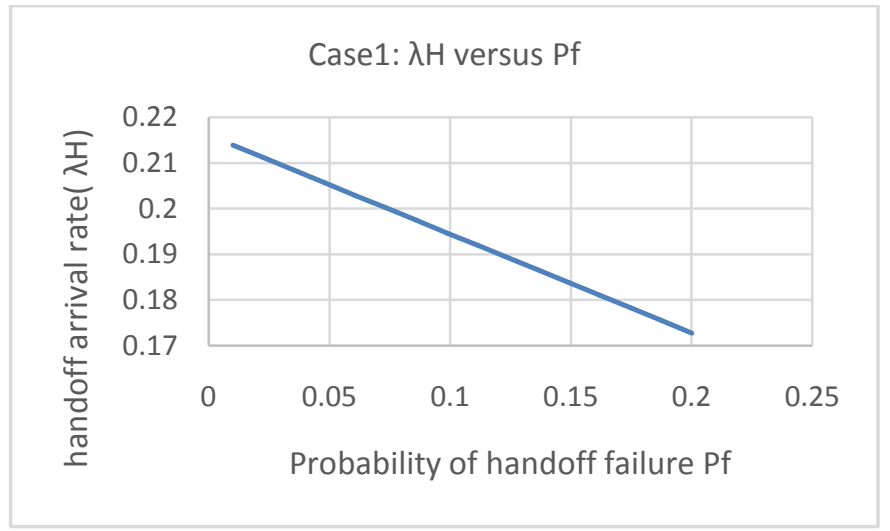

Figure5. Handoff calls arrival rate $\lambda_{H}$ versus $P f$, case1

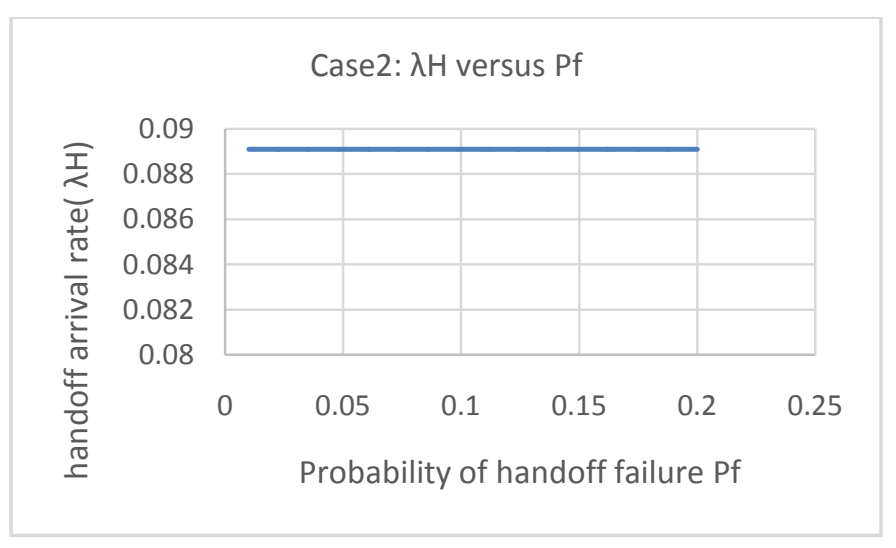

Figure6. Handoff call arrival rate $\lambda_{H}$ versus $P f$, case 2 


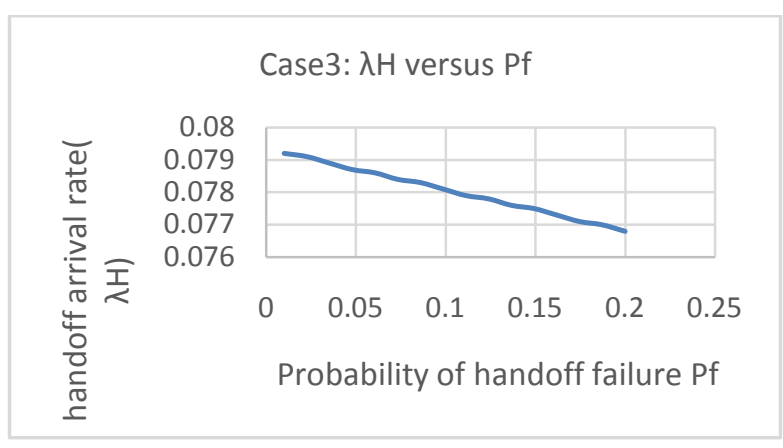

Figure7. Handoff calls arrival rate $\lambda_{H}$ versus $P f$, case 3

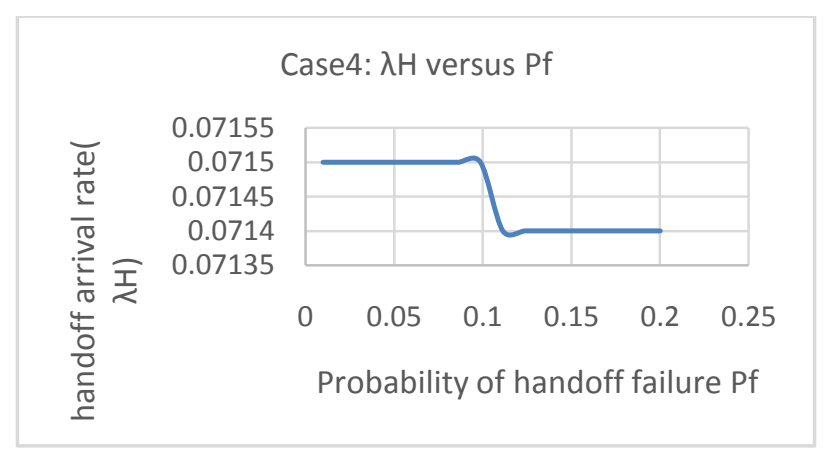

Figure8. Handoff call arrival rate $\lambda_{H}$ versus Pf, case 4

Table4. Handoff call rate $\lambda_{H}$ versus Bo

\begin{tabular}{|c|c|c|c|c|}
\hline Bo & $\lambda_{\mathrm{H}}($ case1 $)$ & $\lambda_{\mathrm{H}}($ case2 $)$ & $\lambda_{\mathrm{H}}($ case3) & $\lambda_{\mathrm{H}}($ case4) \\
\hline 0.0100 & 0.2139 & 0.0891 & 0.0792 & 0.0715 \\
\hline 0.0120 & 0.2135 & 0.0889 & 0.0791 & 0.0713 \\
\hline 0.0140 & 0.2130 & 0.0888 & 0.0789 & 0.0712 \\
\hline 0.0160 & 0.2126 & 0.0886 & 0.0787 & 0.0710 \\
\hline 0.0180 & 0.2122 & 0.0884 & 0.0786 & 0.0709 \\
\hline 0.0200 & 0.2117 & 0.0882 & 0.0784 & 0.0707 \\
\hline 0.0220 & 0.2113 & 0.0880 & 0.0783 & 0.0706 \\
\hline 0.0240 & 0.2109 & 0.0879 & 0.0781 & 0.0705 \\
\hline 0.0260 & 0.2104 & 0.0877 & 0.0779 & 0.0703 \\
\hline 0.0280 & 0.2100 & 0.0875 & 0.0778 & 0.0702 \\
\hline 0.0300 & 0.2096 & 0.0873 & 0.0776 & 0.0700 \\
\hline 0.0320 & 0.2091 & 0.0871 & 0.0775 & 0.0699 \\
\hline 0.0340 & 0.2087 & 0.0870 & 0.0773 & 0.0697 \\
\hline 0.0360 & 0.2083 & 0.0868 & 0.0771 & 0.0696 \\
\hline 0.0380 & 0.2078 & 0.0866 & 0.0770 & 0.0694 \\
\hline 0.0400 & 0.2074 & 0.0864 & 0.0768 & 0.0693 \\
\hline
\end{tabular}

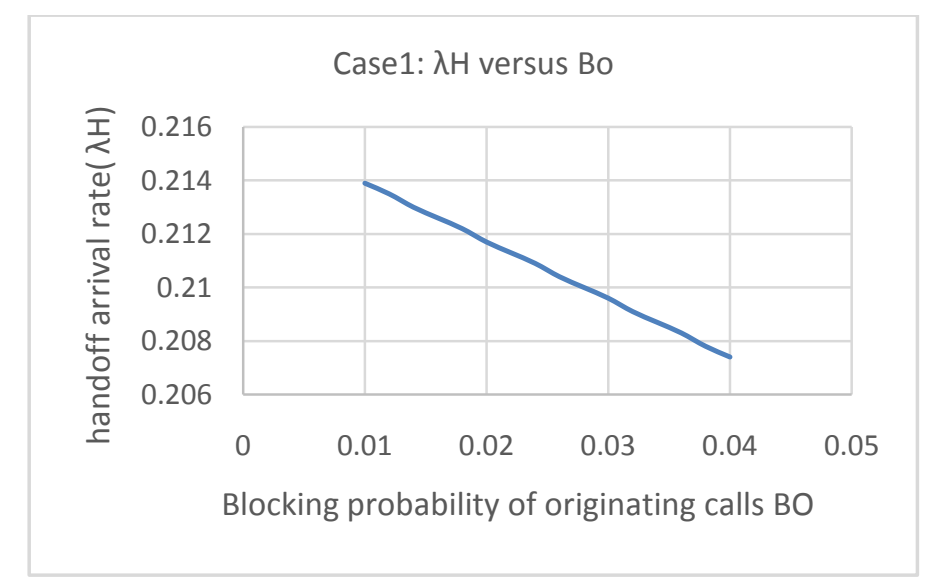

Figure9. Handoff call arrival rate $\lambda_{H}$ versus $\mathrm{Bo}$, case 1 


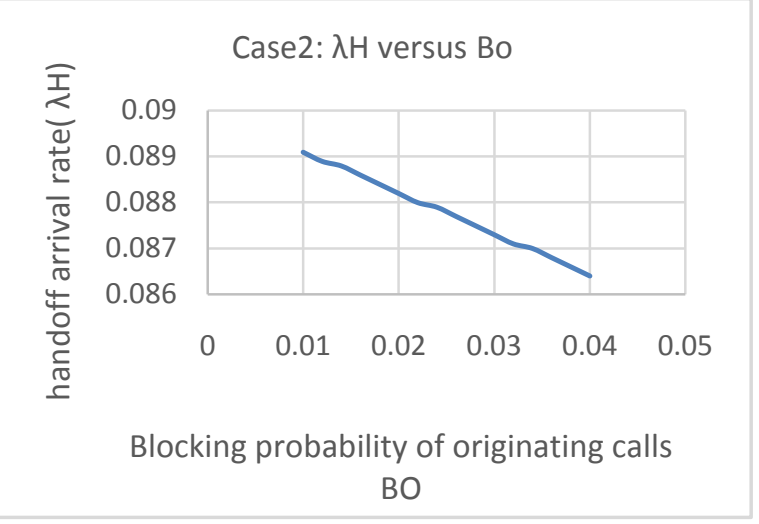

Figure10. Handoff call arrival rate $\lambda_{H}$ versus $B o$, case 2

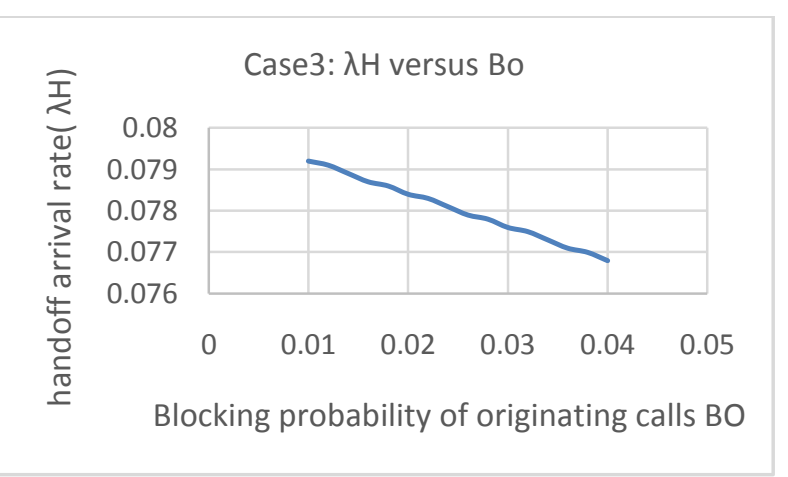

Figure11. Handoff call arrival rate $\lambda_{H}$ versus $B o$, case 3

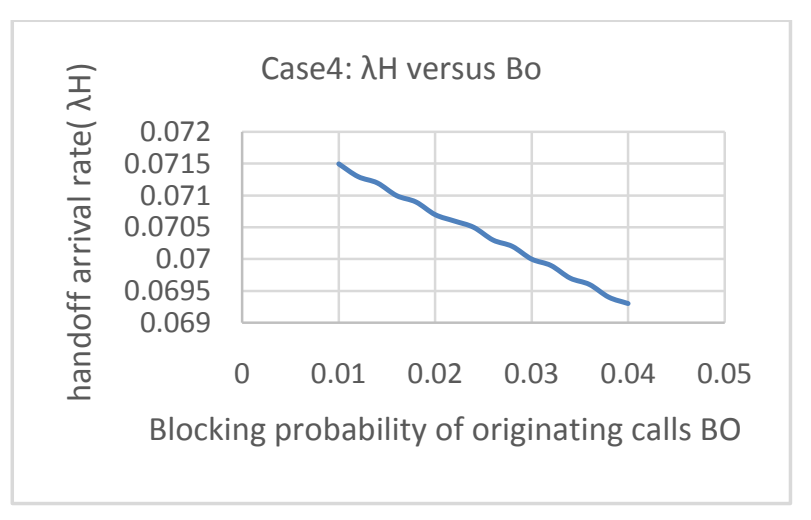

Figure12. Handoff call arrival rate $\lambda_{H}$ versus Bo, case 4

Throughout the overall analysis, group two parameters are evaluated. Firstly, according to the table 2 and figures $1,2,3,4$ show that $P_{l}$ is calculated at minimum and maximum values of its group one parameters. It is noted that as the group one parameters changed to its maximum values, the $\lambda_{\mathrm{H}}$ tend to be unchanged over wider ranges than the previous one. Generally, $P_{l}$ is directly proportional to the $\lambda_{\mathrm{H}}$ especially case 4 which depending on the $P_{h h}$ rather than other parameters such as $\lambda_{0}, \beta$, and $\mathrm{P}_{\mathrm{h}}$. Secondly, referring to the table 3 and figures $5,6,7,8, P_{f}$ is inversely proportional to the $\lambda_{\mathrm{H}}$ case 1 that depending upon the maximum value of $\lambda_{\mathrm{o}}$ at 0.3 , whereas in case 2 the $P_{f}$ has no effect on $\lambda_{\mathrm{H}}$ irrespective of the other parameters in group one. Case 3 is less sensitive than case 1 because of maximum value of $P_{h}=0.98$. In case 4 , there is no change in $\lambda_{\mathrm{H}}$ at range $(0.01-0.0987)$ and range $(0.11-0.2)$ of $P_{f}$, so the only variation is happened at the transition value from $(0.0987-0.124)$ of $P_{f}$. $B o$ is inversely proportional to the $\lambda_{\mathrm{H}}$ in all cases. Throughout the performance analysis, it is found that Bo has stronger effect depending on $\lambda_{o}$ as shown in table 4 case 1 . But $P_{f}$ has low effect as clearly stated in table 3 cases 1 and 3 , whereas case 3 has absolutely no effects

\section{CONCLuSion}

The system is analyzed by the mathematical Steele and Nofal traffic model; it gives good results regarding the effect of the Bo, P1, and Pf. This analysis is so ad equated to the microcell where there 
is low capacity and non density populated area and the users are normally moving on different speeds and directions all the time they spend in the cell such as city or high way streets, market especially the malls, and underground stations. The only constrains that challenges the system and make the results are irrelevant if the users are not in moving mode from one cell to another.

\section{REFERENCES}

[1] Gunnar Heine,"GSM Networks: Protocols, Terminology and Implementation", Artech House mobile communications library, ISBN 0-89006-471-7, 1998.

[2] Jahangir khan, "Handover management in GSM cellular system", International Journal of Computer Applications, Vo 8, No.12, October 2010

[3] Martin Sauter, "From GSM to LTE and introduction to mobile networks and mobile broadband", ISBN 978-0-470-66711-8 (cloth), published John Wiley \& Sons Ltd, 2011.

[4] Abhinav Kumar, Hemant Purohit, A comparative study of different types of handoff strategies in cellular systems, "International Journal of Advanced Research in Computer and Communication Engineering", Vol. 2 Issue, 11 November 2013.

[5] Ivan Stojmenovic," Handbook of Wireless Networks and Mobile Computing", John Wiley \& Sons, ISBNs: 0-471-41902-8, 2002.

[6] Fried helm Hillenbrand, "GSM and UMTS the Creation of Global Mobile Communication", John Wiley \&Sons Ltd, ISBN 0-470-84322-5, 2001.

[7] Kin K. Leung, "Traffic Models for Wireless Communication Networks" IEEE Journal on Selected Areas in Communication, VOL. 12, NO. 8, October 1994.

[8] Biswajit Bhowmik, "A Comparison Study on Selective Traffic Models with Handoff Management Scheme for Wireless Mobile Network Infrastructure", International Journal of Information Technology and Computer Science, 02, 66-72, 2013.

\section{AUTHORS' BIOGRAPHY}

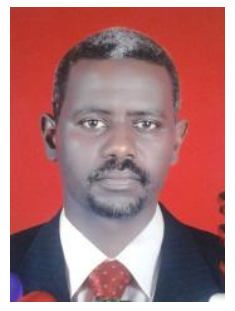

Elsanosy M. Elamin, obtained his BSc in Electrical and Computer Engineering at Omdurman Islamic University 1999. Received his MSc. in Communication at Karary Academy of Technology 2003 and Ph.D. in Electronics at Sudan Academ of Sciences 2014. Assistant Professor, head department of electrical engineering, University of Cordovans and now coordinator of post-graduate studies. His field interest is in Electronic Circuit Design, Data Communication Networks, and Mobile Communication Networks.

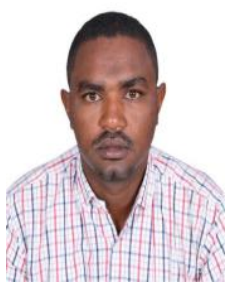

Basil B. Ahmed Abdelrahim, Received the BSc degree in Electrical Engineering at Kordofan University, Elobeid, Sudan, in 2018. Currently working as electric engineer at Shabakkat System Dynamics CO. LTD supported for ZAIN network, Maintenance Power (corrective \& preventive), Generates Maintenance \& installation \& A/Cs maintenance (A/c unit - A/c controller), Electrical Maintenance (MDB, lighting, ATS), and Hybrid System.

Abdelrhman Y. Adam, Received his BSc. in Electrical Engineering at faculty of Engineering, University of Kordofan, 2018

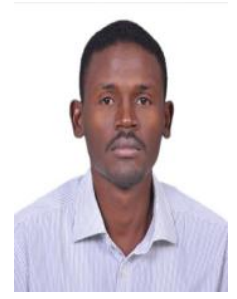

Mohammed H, Mohammed. Obtained his diploma in electrical engineering in 2013, College of engineering and technical studies, University of Kordofan. Received his BSc. in electrical engineering (Power) in 2018, University of Kordofan. He worked at ministry of physical planning and public 2016. Now he is electrical engineer at the ministry of water resources, energy and mining.

Citation: E. M. Elamin et.al, "Analysis of Handoff Call Rate in Microcell of GSM Networks by Steele and Nofal Traffic Model", International Journal of Research Studies in Electrical and Electronics Engineering, 4(1), pp 35-41. DOI: http://dx.doi. org/10.20431/2454-9436.0401004

Copyright: (C) 2018 E. M. Elamin et.al. This is an open-access article distributed under the terms of the Creative Commons Attribution License, which permits unrestricted use, distribution, and reproduction in any medium, provided the original author and source are credited. 